\title{
From Intercultural Awareness to Intercultural Empathy
}

\author{
Honglin Zhu \\ School of Foreign Languages, Changzhou University \\ Changzhou 213016, Jiangsu, China \\ E-mail: zh157921@yahoo.com.cn
}

\begin{abstract}
This article is concerned with the incorporation of teaching culture into EFL teaching and learning, with a focus on the cultivation of culturally empathic ability for Chinese learners. The article first holds a discussion on the significance and basic concepts concerning intercultural empathy. Furthermore, it makes an attempt to analyze the barriers encountered by Chinese learners in developing culturally empathic ability. Finally, it tries to offer some suggestions and techniques.
\end{abstract}

Key words: Intercultural communication, Empathy, Barriers, Suggestions

\section{Introduction}

EFL learning consists of various components, such as grammatical competence, communicative competence, language proficiency, as well as attitudes towards one's own or another culture. However, in the past decades, there are still some deeply ingrained beliefs about the nature of language teaching and learning-beliefs that influence methodology as well as the content of the foreign language curriculum, which have gradually and insidiously undermine the teaching and learning of culture.

Among some deeply ingrained beliefs about the nature of language learning and teaching, one of the misconceptions that have long dominated the field in foreign language teaching is the conviction that language learning is to a large extent a decoding process and this belief has given to various approaches to foreign language teaching. However, with the passage of time, most EFL teachers in China have been increasingly aware of the fact that foreign language learning is foreign culture learning, and that to cultivate students' competence for intercultural communication, teachers need first to arouse their cultural awareness. And, as a trend, culture has implicitly or explicitly been taught in the foreign language classroom. What remain to be clarified, though, is what is meant by the notion "cultural awareness" and how it is integrated into language learning and teaching.

\section{Intercultural awareness vs. intercultural empathy}

Intercultural awareness can be regarded as the foundation of communication. It involves two qualities: one is the awareness of one's own culture; the other is the awareness of another culture. In other words, it involves the ability of standing back from our own point and becoming aware of not only our own cultural values, beliefs and perceptions, but also those of other cultures. Cultural awareness becomes essential when people communicate with people from other cultures. Because people see, interpret and evaluate things in different ways, what is considered as appropriate in one culture is likely to be inappropriate in another, and therefore, misunderstandings arise when people communicate. For example, as a Chinese, his intuition on seeing an American is probably as the one who always work, wear casual clothes, eat fast food, drink coca cola and talk about business over lunch. These impressions more or less reflect that the meaning people giving to certain activities, like having lunch or dinner could be different in contrast to certain cultures. In China, where relationships are highly valued, lunch, dinner or a gathering for tea has a social connotation: people get together to talk and relax, and more importantly, to build an intimate relationship. Misinterpretations occur primarily when we are not aware of our own behavioral rules and project them onto others. In absence of cultural awareness, we tend to misinterpret the verbal or the non-verbal behavior of the person with whom we interact.

However, the mere realization of cultural awareness is far from sufficient. As an effective way to develop their communicative competence, language learners in cross-cultural situations, especially Chinese FL learners with eastern cultural background, should try by every means to cultivate empathetic concepts and precepts in the process of foreign language learning.

As a word from the Greek "empatheia", empathy means understanding others by entering their world,or "standing in somebody else's shoes". The empathy in foreign language learning and intercultural communication is what we call intercultural empathy, which means placing himself into the cultural background of the target language and being able to effectively communicate his understanding of that world. 
In China, the notion of empathy is to a large extent influenced by Chinese traditional values; as a consequence, current practice regarding empathy rarely takes into account cross-cultural effects. Therefore, it has been suggested that there is a need to explore the issue of intercultural empathy. Ibrahim (1991) identified the need to "convey empathy in a culturally consistent and meaningful manner" when working with culturally diverse group.

\section{The significance of intercultural empathy}

The ability to be culturally empathic is of great significance in many ways.

First, it is the prerequisite and assurance for effective cultural communication. Empathy leads us not only to experience the feelings of another but also to reflect on those feelings and compare them to our own. Only when one truly understands what the other is thinking and behaving, can he be able to get access to ideal communication. When the communicator consciously and willingly shifts from one's own cultural frame of reference and actively projects oneself in another culture, without abandoning one's own perspective on the situation, it will bring an active consequence. Chinese might think that the British drive on the "wrong" side of the road. It's not "wrong", it's "left". If one can't describe behavior objectively, he is unlikely to understand that behavior. However, it's important to emphasize that cultural empathy is not sympathy with, agreement with or identification with a specific culture. Rather, it is the appropriate understanding of a culture's values and beliefs; it has been described as "seeing the world through another's eyes, hearing as they might hear, and feeling and experiencing their internal world," which does not involve "mixing your own thoughts and actions with those of the client" (Ivey, Ivey, \& Simek-Morgan, 1997). Therefore the culturally empathic languages learners retain their separate cultural identity and simultaneously are aware of and accept the cultural values and beliefs of the people with different cultural background. In this sense, one doesn't need to agree with those values and beliefs to understand them and one doesn't need for his culture to be like that culture to have empathy.

Second, intercultural empathy is essential in helping people build a good relationship and achieve a smooth intercultural communication. In intercultural communication, people usually exhibit a variety of personal differences in their empathy ability. By applying knowledge about their own and other's cultures and consciously shift into a different culture, they can empathize or take another person's perspective in order to understand and be understood across cultural boundaries. In addition, people can go beyond personal boundaries and try to learn about the experiences of people who are different from their own, so as to know others with an empathic eye.

To sum up, the ability of intercultural empathy is a mirror of one's competence reflecting his understanding of the emotional states of people in the target culture, so as to minimize the psychological barriers caused by the target culture.

\section{Barriers in intercultural empathy}

As is discussed previously, intercultural empathy does not mean to cast aside one's native culture, but a rational understanding and acceptance of the cultural differences shown in the target culture (though different cultures do share some universals). Based on such understanding, we may assume some primary causes which are predominantly involved in the process of cultivating intercultural empathy:

1) The unawareness of the target culture, and the lack of contact with people of that culture;

2) Overstressing the universals of cultures, but neglecting the differences between them;

3) The differences in people's patterns of thinking and their negative transfer into the target culture when learning the target language;

4) Learners' indiscriminate application of their cultural customs to the target culture.

To be more specific, the following factors contribute to the barriers of intercultural empathy in FL learning.

\subsection{Stereotype}

Stereotypes are outgrowth of cultural interaction and misperception. They are individuals' "naive" perceptions of particular groups that are shaped by their personal value system through their cognitive schemata. Positive stereotypes, such as "intelligent" and "ambitious," and negative stereotypes, such as "retarded" and "lazy," signify membership in specific social groups and allow individuals to cognitively sort through an abundance of information based on salient features. Although stereotypes should never be applied to describe individual behavior (it should be applied to the behavioral norm for the entire group), people consistently utilize this "first best guess" incorrectly into their perception of individual ethnic and cultural minorities (Adler, 1986). For example, in American society, there is such a stereotype about Chinese that their intelligence excels at mathematics and science. This stereotype is reinforced in news reports that Chinese-American students score much higher on math exams than their White counterparts and that the percentage of U.S. scientists who are Asian-American is two to three times the percentage 
of Asian-Americans in the total population. Stereotypes provide us with role expectations, i.e. how we expect the other person or group to relate to us and to other people. "Our culture has hundreds of ready-made stereotypes: leaders are dominant, arrogant men; housewives are nice but empty headed; teenagers are music crazed car-fanatics; France men are romantic; Germanys are strict; Americans are causal; Japanese are hard-working" and on and on" (Tucker-Ladd, Clayton E. 2000). Of course, sometimes a leader or housewife or Germany is somewhat like the stereotype but it is a injustice to automatically assume they all are. In fact, when people stereotype, they are apt to amplify a particular behavior performed by another particular group but ignoring many similarities.

\subsection{Prejudice}

Prejudice is a premature judgment or a negative attitude towards a person or group of people which is not based on objective facts. These prejudgments are usually based on stereotypes which are oversimplified and over generalized views of groups or types of people (Tucker-Ladd, Clayton E.). The prejudgment may be based on an emotional experience people have had with a similar person, sort of their own personal stereotype. For example, in the eyes of some Americans, Hispanics are lazy people, although this is by no means the case. Some Americans also portray mainly blacks as gang members and drug dealers and this is reinforced as stereotypes, and therefore, grinds away at all African Americans' sense of respect and self-esteem.

When we are prejudiced, we violate three standards: reason, justice, and tolerance. We are unreasonable if we judge others negatively without evidence or in spite of positive evidence or use stereotypes without allowing for individual differences. We are intolerant if we reject or dislike people because they are different, e.g. of a different religion, different socioeconomic status, or have a different set of values. We violate all three standards when we have a scapegoat, i.e. a powerless and innocent person we blame for something he or she didn't do. Prejudiced people may fall victim to errors in the processing and recall of information regarding the objects of their negative feeling: Such individuals will, over time come to think of their "targets" in a certain way, and effectively will filter out or ignore information inconsistent with or contrary to what they have come to believe about those targets.

\subsection{Lack of cultural sensitivity}

Cross cultural sensitivity is the quality of being aware and accepting of other cultures. A person who is not culturally sensitive is liable to ignore the differences between their culture and another person's, and as a consequence, the ignorance might affect their relationship and the way they communicate with each other. For example, there is an American Company that manufactures golf balls packaged the balls in packs of four. They were successful and began selling internationally. However their sales performance was not successful in Japan, where the number four holds the meaning of death. Similarly, a Chinese manufacturer of batteries used to export to Europe their batteries with "White Elephant" as brand name, ignorant of the connotation of the term in English language-something costly or troublesome, useless to its owner!

Cultural sensitivity does not mean, however, that a person need only be aware of the differences to interact effectively with people from other cultures. It means being aware that cultural differences and similarities exist and have an effect on values, learning and behavior (Stafford, Bowman, Eking, Hanna \& Lopoes-DeFede, 1997). The lack of cultural sensitivity owes much debt to the following factors:

\subsubsection{The ignorance of differences in thought patterns}

Different cultures give birth to different thought patterns. Based on the logic system of Greece, western thought patterns are quite different from those of Chinese. For example, the western line of argument is generally deductive, with a topic introduced at the beginning and followed by the minor or supporting arguments. This pattern contrasts with the Chinese inductive pattern, in which minor points of the argument are placed first and then the main point is presented.

Another point is that westerners tend to be "analytic" (beginning with the separate parts and piecing them together to make a whole) as opposed to the Chinese "global" tendency. Besides, in western culture, being straightforward is regarded as an acceptable manner in communication, while in Chinese culture, being implicit is more appreciated.

\subsubsection{The ignorance of differences in values, norms and beliefs}

The system that includes values, norms and beliefs shape the behavior of the members of a culture. This system has the characteristics of being unique, enduring, and relatively stable. If the intercultural communicators are ignorant or unaware of the existence of this system, they will find it difficult to be empathic. For example, in English culture, both animals and humans have feelings, get sick, and are buried in cemeteries. In Chinese culture, however, the distinction between humans and animals is great, and burring animals is unlikely to take place (if there are such cemeteries). Another similar example is about people's belief on numbers. In China the number "4" (which is related to "death" according to Chinese pronunciation) is considered unlucky in much the same way western people 
consider the number "13". For this reason, the 4th, 14th Floors of a building will be renamed 3A, 13A or just skipped.

Owing to the ignorance of differences in values, norms and beliefs, People are often surprised or even shocked to learn that the countries they visit are very different with what they had anticipated. For instance, an American teacher who once had a short visit to China had the impression that many young Chinese were homosexuals. The reason was that he saw many young people of the same sex walk hand in hand, while the truth is that in most cases it is merely a sign to show friendship, having nothing to do with homosexuality.

\section{Conclusion}

In summary, cultural empathy is an important capacity for coping with intercultural problems adequately, effectively and satisfactorily. Through the previous discussion, we may safely conclude that desirable communication depends on the interplay of many factors and it may end in failure owing to our stereotypes, prejudice and lack of cultural sensitivity. Effective communication can be enhanced when empathy is conveyed and the ability in intercultural empathy can be developed by consistently trying to put your feet in another's shoes. To achieve this goal, the following suggestions might be of help:

1) Be persistent in maintaining open communication. If miscommunication occurs, view it as a problem to be solved and an opportunity to find ways to communicate.

2) Be sensitive to the fact that there are basic differences in the ways people of different cultures communicate, such as through the different use of words, voice and body language. Be willing to value and recognize the importance of one's own culture and be willing to learn about the traditions and characteristics of other cultures.

3) Be honest and willing to take risks, make mistakes and be flexible in your communication style.

4) Think about and examine the cultural basis of your own belief system when trying to when trying to understand the culture of another person. Being culturally empathic means being nonjudgmental and recognizing that although differences may exist base on culture, communication can still continue.

5) Take active interest in the culture and norms of other person. A willingness to adapt one's communication and behavior to be compatible with another's cultural norms. The more you know about a certain culture, the better the chances for effective communication. Besides, openness, caring and mutual respect of the dignity of individuals are essential qualities for intercultural empathy regardless of cultural differences.

\section{References}

Adler, N.J. (1986). International Dimensions of Organizational Behavior. Massachusetts, Kent Publishing.

Goodenough, W. H. (1981). Culture, Language, and Society. London: The Benjamin / Cummings Publishing Company.

Ibrahim, F.A. (1991). Contribution of Cultural Worldview to Generic Counseling and Development. Journal of Counseling and Development, 70, 13-19.

Ivey, A.E. Ivey, M.B., \& Simek-Morgan, L. (1997).Counseling and Psychotherapy: A Multicultural Perspective, Fourth, Edition. Boston: Allyn and Bacon.

Kramsch, C. (1993). Context and Culture in Language Teaching. Oxford: Oxford University Press.

Robinson, G. L. (1985). Cross-cultural Understanding: Processes and Approaches for Foreign Language: English as a Second Language and Bilingual Educators. Oxford: Pergamon.

Stafford, J.R., Bowman, R., Ewing, T., Hanna, J., \& Lopez-De Fede, A. (1997). Building Culture Bridges.

Bloomington, IN: National Educational Service.

Stern, H. H. (1983). Fundamental Concepts of Language Teaching. Oxford: Oxford University Press. 